\title{
Depression of Excitatory Synapses onto Parvalbumin Interneurons in the Medial Prefrontal Cortex in Susceptibility to Stress
}

\author{
Zinaida Perova, ${ }^{-K}$ Kristen Delevich, and Bo Li \\ Watson School of Biological Sciences, Cold Spring Harbor Laboratory, Cold Spring Harbor, New York 11724
}

In response to extreme stress, individuals either show resilience or succumb to despair. The prefrontal cortex (PFC) is required for coping with stress, and PFC dysfunction has been implicated in stress-related mental disorders, including depression. Nevertheless, the mechanisms by which the PFC participates in stress responses remain unclear. Here, we investigate the role of parvalbumin (PV) interneurons in the medial PFC ( $\mathrm{mPFC}$ ) in shaping behavioral responses to stress induced by the learned helplessness procedure, in which animals are subjected to an unpredictable and inescapable stressor. PV interneurons in the MPFC were probed and manipulated in knock-in mice expressing the Cre recombinase under the endogenous parvalbumin promoter. Notably, we found that excitatory synaptic transmission onto these neurons was decreased in mice showing helplessness, a behavioral state that is thought to resemble features of human depression. Furthermore, selective suppression of PV interneurons in the mPFC using hM4Di, a DREADD (designer receptor exclusively activated by designer drug), promoted helplessness, indicating that activation of these neurons during stress promotes the establishment of resilient behavior. Our results reveal a cellular mechanism of mPFC dysfunction that may contribute to the emergence of maladaptive behavioral responses in the face of adverse life events.

Key words: depression; learned helplessness; medial prefrontal cortex; parvalbumin interneuron; stress; synapse

\section{Introduction}

Dysfunction of the PFC has been implicated in depression (Drevets et al., 2008), for which stress is a major risk factor (Kendler et al., 1999). Notably, stress causes structural and functional changes in the medial PFC (mPFC), including retraction of dendrites, loss of spines (Dias-Ferreira et al., 2009; Goldwater et al., 2009), and altered synaptic transmission (Yuen et al., 2011; Wang et al., 2014). Our previous study indicated that stress can induce opposing changes in excitatory synapses onto mPFC pyramidal neurons (Wang et al., 2014). Specifically, synaptic potentiation and depression are associated with susceptibility and resilience, respectively, to learned helplessness (Wang et al., 2014), a depression-like phenotype whereby animals show a reduction in escape from an escapable stressor (Maier, 1984; Chourbaji et al., 2005; Li et al., 2011). Changes in measures of excitatory drive

Received July 1, 2014; revised Jan. 3, 2015; accepted Jan. 13, 2015.

Author contributions: Z.P. and B.L. designed research; Z.P. and K.D. performed research; Z.P. and K.D. analyzed data; Z.P. and B.L. wrote the paper.

This work was supported by a Charles A. Dana Fellowship (Z.P.) and the National Institutes of Health, the Dana Foundation, the National Alliance for Research on Schizophrenia and Depression, and the Louis Feil Trust (B.L.). We thank members of the B.L. laboratory for discussions; F. Henn, Z. J. Huang, S. Shea, P. Osten, and L. Van Aelst for suggestions, B. Ujfalussy for discussions on statistical analysis; J. Huang for help with R programming; and P. Smith for reading this manuscript.

The authors declare no competing financial interests.

Correspondence should be addressed to either of the following: Dr. Bo Li, Cold Spring Harbor Laboratory, 1 Bungtown Road, Cold Spring Harbor NY 11724, E-mail: bli@cshl.edu; or Dr. Zinaida Perova, MRC Laboratory of Molecular Biology, Cambridge CB2 0QH, UK, E-mail: zperova@mrc-Imb.cam.ac.uk.

Z. Perova's present address: MRC Laboratory of Molecular Biology, Cambridge CB2 OQH, UK.

DOI:10.1523/JNEUROSCI.2670-14.2015

Copyright $\odot 2015$ the authors $\quad 0270-6474 / 15 / 353201-06 \$ 15.00 / 0$ in the PFC have also been observed in postmortem studies on patients with major depression (Price and Drevets, 2012). Together, these findings suggest that synaptic and other cellular changes in the mPFC might be critical contributors to the pathophysiology of depression.

An essential component of the mPFC microcircuits is the inhibitory network composed of distinct classes of interneurons, which exert exquisite control over pyramidal neurons. Dysfunction of cortical inhibitory interneurons has been implicated in major psychiatric disorders. In particular, impaired function or reduced number of interneurons in the MPFC has been associated with depression and bipolar disorder (Rajkowska et al., 2007; Savitz et al., 2014). However, the nature of these changes and their role in the pathogenesis of mood disorders are unknown.

In the current study, we investigated the stress-induced alterations in synapses onto a major class of inhibitory interneurons - the parvalbumin (PV) interneurons - in the mPFC in mice subjected to the learned helplessness $(\mathrm{LH})$ procedure. We also selectively manipulated the activity of these neurons to assess their role in the establishment of behavioral responses to stress.

\section{Materials and Methods}

Animals. Mice were group housed under a $12 \mathrm{~h}$ light/dark cycle (light from 9 A.M. to 9 P.M.), with food and water available ad libitum. The PV-Cre, Ai14, and Rosa26-loxp-STOP-loxp-H2B-GFP mice were described previously (Hippenmeyer et al., 2005; Madisen et al., 2010; He et al., 2012). All mice were bred onto the C57BL/6N background for at least five generations. Wild-type C57BL/6N mice were purchased from Taconic. Male mice of 5-6 weeks old were used. The age of mice was 
A

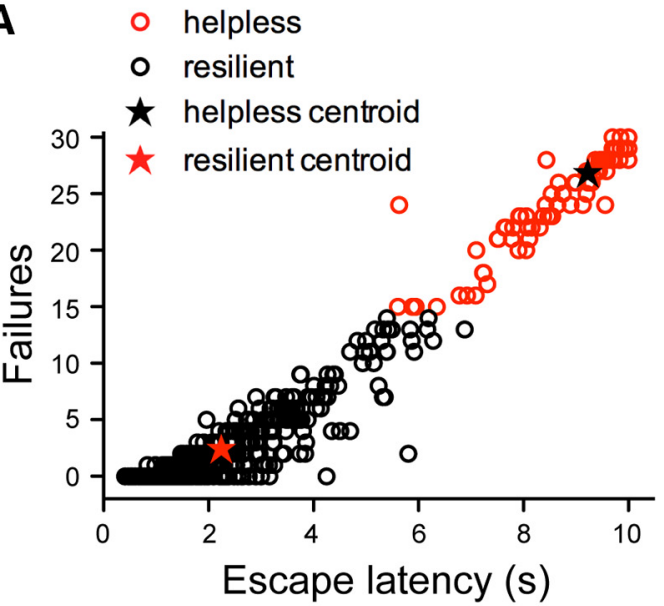

C

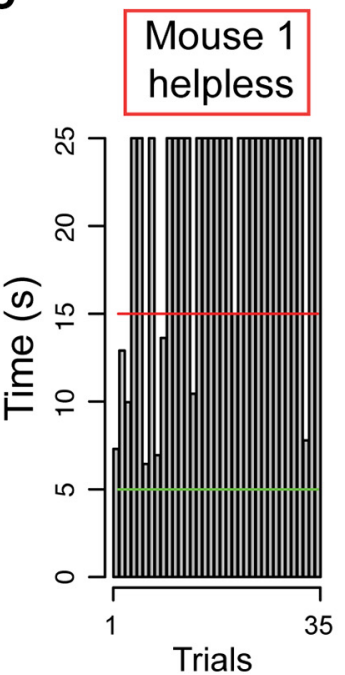

Mouse 2 helpless

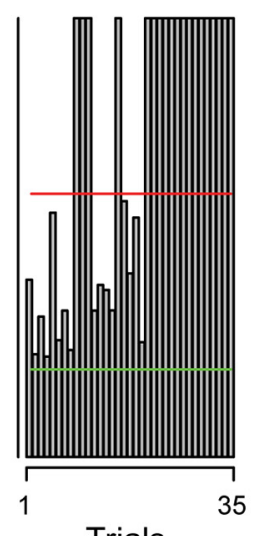

B

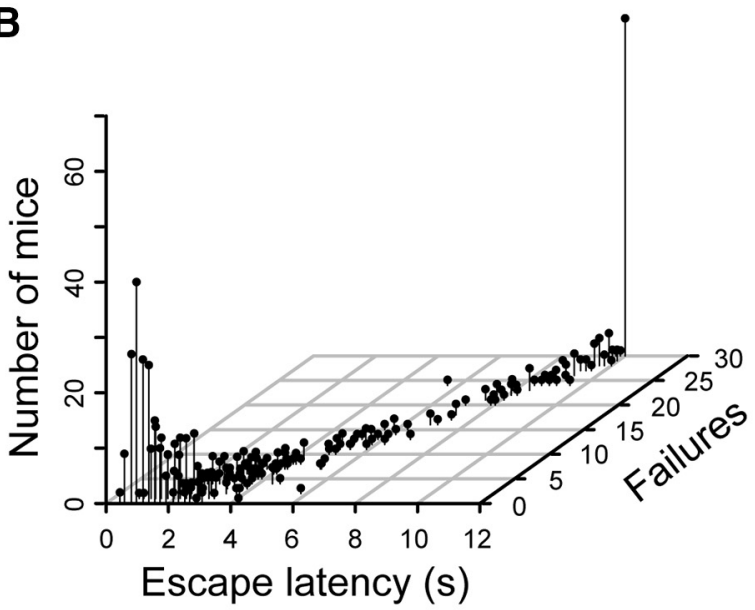

Mouse 3 resilient

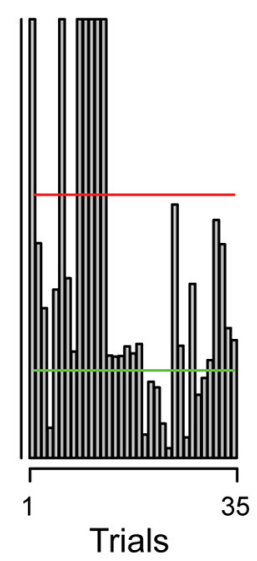

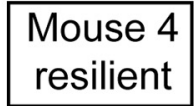

Criteria
for scoring

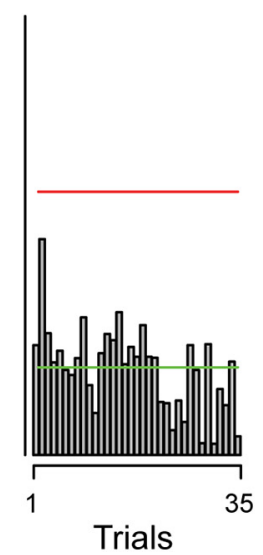

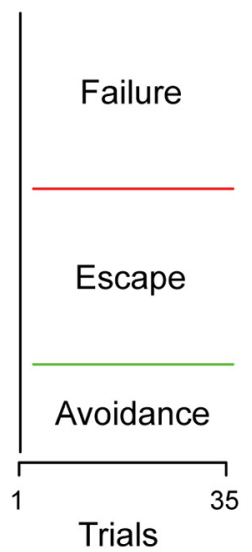

Figure 1. Classification of stress-induced resilient and helpless behavior. $A$, A graphic representation of the behavioral measurements (escape latency and failures) for all mice used in this study. A $k$-means cluster analysis defined two distinct clusters, the "helpless" and "resilient," among a total number of 574 mice. The centroids for helpless and resilient mice are (9.23, 26.83) (black star) and $(2.24,2.42)$ (red star), respectively. $\boldsymbol{B}, A 3 \mathrm{D}$ scatterplot of the same data shown in $\boldsymbol{A}$. The position of each dot along the $z$-axis represents the number of mice showing a specific set of behavioral parameters. C, Behavioral measurements from four representative mice. Each graph reflects the time ( $y$-axis) an animal took to finish each of the 35 trials ( $x$-axis) in a testing session (see Materials and Methods). Trials that were ended within $5 \mathrm{~s}$ (bars below the green line) represent avoidance; trials that were ended within $15 \mathrm{~s}$ (bars below the red line) represent escape. The remaining trials represent failure (see the rightmost panel, "criteria for scoring"). Mice 1 and 4 (marked by a red box and black box, respectively) were mice with extreme behavioral measurements, and they were chosen for further experiments.

matched for each experiment. All procedures involving animals were approved by the Institute Animal Care and Use Committees of Cold Spring Harbor Laboratory.

Behavioral procedures. The LH procedure in mice has been described previously (Chourbaji et al., 2005; Wang et al., 2014). Mice were first exposed to two induction sessions that were separated by $24 \mathrm{~h}$. Each session consisted of 360 inescapable, uncontrollable electric foot shocks over a 60 min period. The shock intensity was set at $0.3 \mathrm{~mA}$, the duration of each shock was randomized between 1 and $3 \mathrm{~s}$, and the intershock intervals (ITIs) were randomized between 1 and $15 \mathrm{~s}$.

At $24 \mathrm{~h}$ after the second induction session, mice were subjected to a testing session. The testing, fully automated using Graphic State 3.0 software (Coulbourn Instruments), was performed in a shuttle box $(14 \times$ $7 \times 12$ inches; Coulbourn Instruments) equipped with an electrical grid floor, a door separating the two halves, and photocell detectors. The shuttle box was placed in a sound-attenuating chamber. Mice explored the shuttle box for $2 \mathrm{~min}$, and behavioral performance was evaluated over 30 trials of escapable foot shocks $(0.3 \mathrm{~mA}$ intensity, $10 \mathrm{~s}$ duration, with ITIs of $30 \mathrm{~s}$ ). Each trial started with a $5 \mathrm{~s}$ cue light, followed by the foot shocks. When an animal shuttled to another compartment of the box during the $5 \mathrm{~s}$ cue light presentation (and therefore before the shock onset), avoidance was scored. If the animal shuttled during the $10 \mathrm{~s}$ shocks (i.e., escaped), escape latency was measured. Failure was recorded if no shuttling was made during the $10 \mathrm{~s}$ shock presentation. Shock was terminated if the animal shuttled to another side of the box (in case of escape) or at the end of the $10 \mathrm{~s}$ shock (in case of failure).

Animals' behavior was classified as being "resilient" or "helpless" based on their behavioral parameters in the LH testing session. A $k$-means $(k=2)$ cluster analysis was applied to a database consisting of 574 mice subjected to the LH procedure (Fig. 1). We used failures and escape latency - the most commonly reported indices of helplessness (Seligman, 1978; Chourbaji et al., 2005; Wang et al., 2014)—as parameters for classification. We further performed a linear discriminant analysis on our clustering results, with the number of failures and escape latency as predictor variables, to obtain classification equations for new cases: $\mathrm{R}=-4.25+(4.5 *$ escape latency $)+(-1.22 *$ failures $)$, and $\mathrm{LH}=$ $-31.03+(2.23 *$ escape latency $)+(1.49 *$ failures $)$, where the escape latency and the number of failures define the classification scores, $\mathrm{R}$ (resilience) and LH (learned helplessness). A mouse is classified as being resilient if $\mathrm{R}>\mathrm{LH}$, or learned helpless if $\mathrm{LH}>\mathrm{R}$. The higher classification score reflects a smaller squared Mahalanobis distance to the centroid of the corresponding group (Chourbaji et al., 2005; Wang et al., 2014).

Open field test (OFT) was performed in a nontransparent box $(42.5 \times$ $42.5 \times 40 \mathrm{~cm}$ ) at least $3 \mathrm{~h}$ before the onset of the dark cycle (Wang et al., 
A
1. Naive
Home cage
$\stackrel{24 \mathrm{~h}}{\longrightarrow}$ Home cage $\stackrel{24 \mathrm{~h}}{\longrightarrow}$
Home cage
$\stackrel{4 \mathrm{~h}}{\rightarrow}$ Recording
2. Resilient
3. Helpless
Induction $\longrightarrow$ Induction
$\rightarrow$ Testing
$\rightarrow$ Recording

B

Naive

Resilient

Helpless
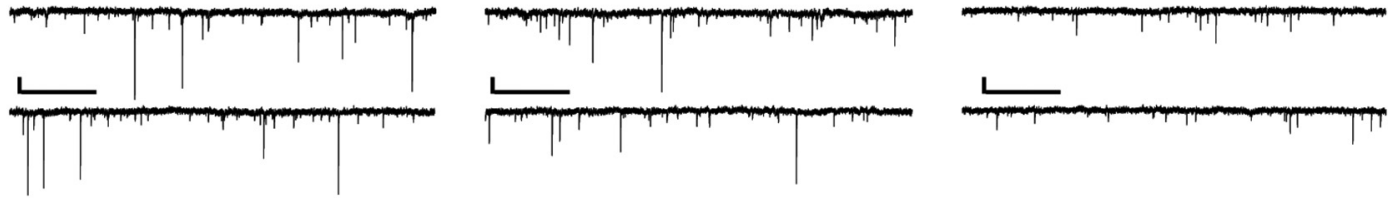

C
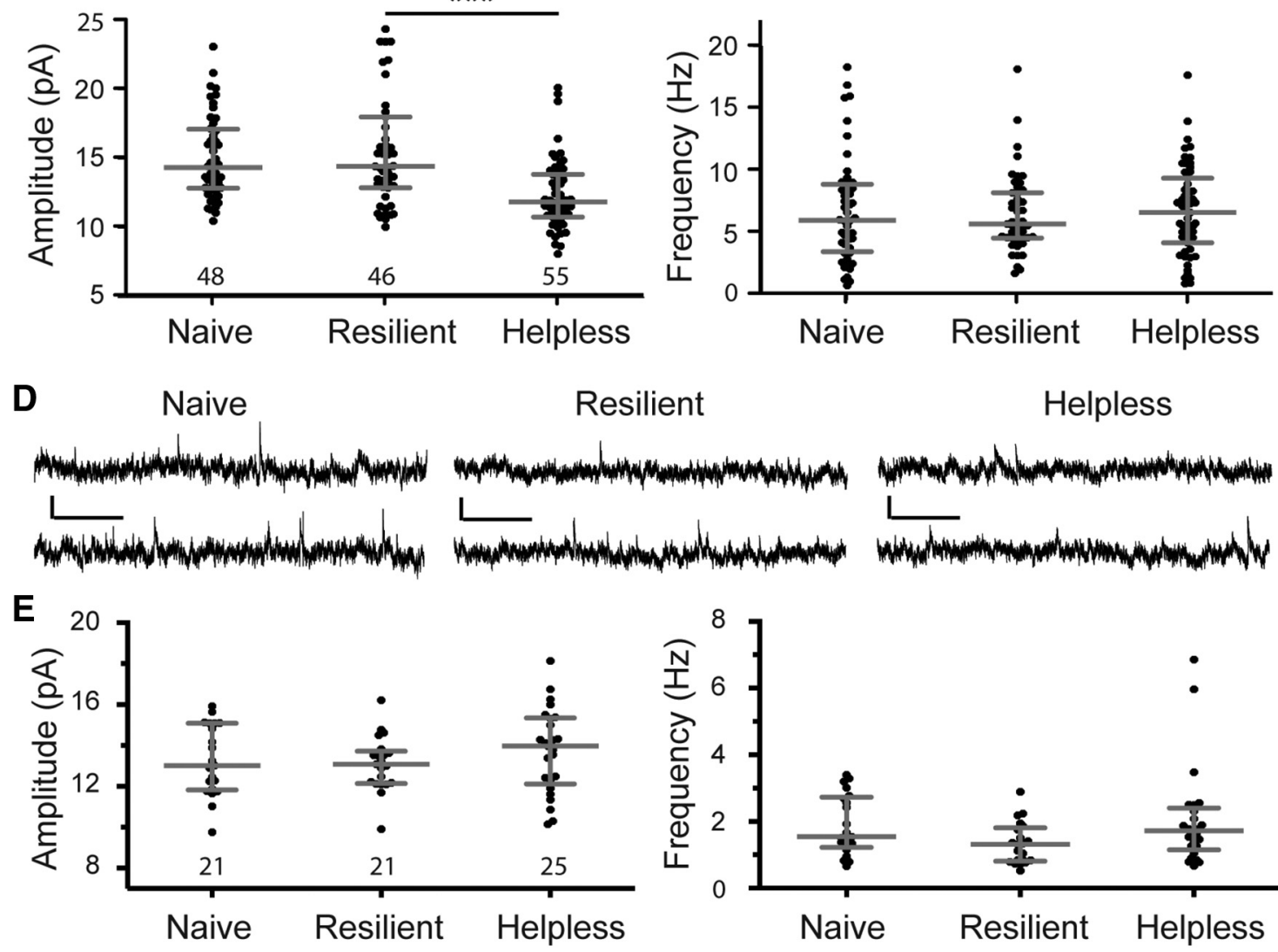

Resilient

Helpless

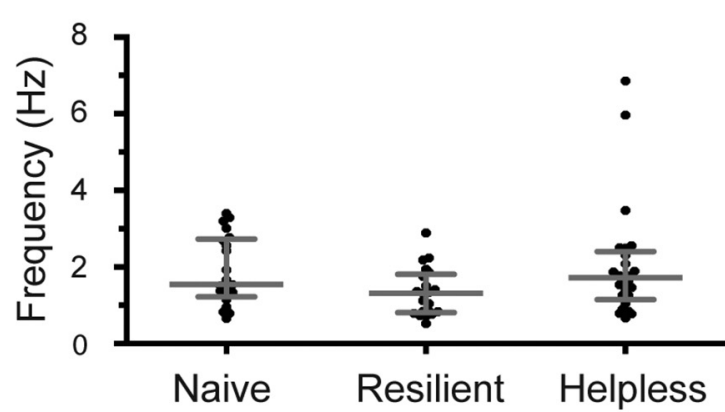

Figure 2. Helplessness is associated with depression of excitatory synaptic transmission onto PV interneurons in the mPFC. $A, A$ schematic of the experimental procedure. $\boldsymbol{B}$, Representative traces of mEPSCs recorded from PV interneurons in the PL region of "naive," "resilient," and "helpless" mice. C, Quantification of mEPSC amplitude (left) and frequency (right; $\left.{ }^{* * *} p<0.001\right)$. $\boldsymbol{D}$, Representative traces of mIPSCs recorded from PV interneurons in the PL region of naive, resilient, and helpless groups. $\boldsymbol{E}$, Quantification of mIPSC amplitude (left) and frequency (right). Data are presented as the median with interquartile range. The numbers in the graphs indicate the number of cells recorded for each group. Calibrations: $10 \mathrm{pA}, 500 \mathrm{~ms}$.

2014). Animals were placed in one of the corners of the arena at the start of each session. The center zone was set to $21 \times 21 \mathrm{~cm}$ in the middle of the arena. Mice explored the arena for $5 \mathrm{~min}$, while being videotaped using a monochrome CCD camera (Panasonic WVBP334) at $4 \mathrm{~Hz}$. Data were analyzed with tracking software Ethovision XT 5.1 (Noldus). The arena was thoroughly cleaned with $70 \%$ ethanol in between subjects.

When mice were subjected to multiple behavioral procedures, the OFT was performed before the LH procedure.

Preparation of acute brain slices and electrophysiology. Acute slices were prepared on the day of the last behavioral session. Mice were anesthetized with isoflurane, decapitated, and their brains quickly removed and chilled in ice-cold dissection buffer [containing (in mM) 110.0 choline chloride, 25.0 $\mathrm{NaHCO}_{3}, 1.25 \mathrm{NaH}_{2} \mathrm{PO}_{4}, 2.5 \mathrm{KCl}, 0.5 \mathrm{CaCl}_{2}, 7.0 \mathrm{MgCl}_{2}$, 25.0 glucose, 11.6 ascorbic acid, and 3.1 pyruvic acid, gassed with $95 \% \mathrm{O}_{2}$ and $5 \% \mathrm{CO}_{2}$ ]. Coronal slices $(300 \mu \mathrm{m})$ containing the $\mathrm{mPFC}$ were cut in dissection buffer using a HM650 Vibrating Microtome (MICROM International) and subsequently transferred to a storage chamber containing artificial CSF [ACSF; containing (in $\mathrm{mm}$ ) $118 \mathrm{NaCl}, 2.5 \mathrm{KCl}, 26.2$ $\mathrm{NaHCO}_{3}, 1 \mathrm{NaH}_{2} \mathrm{PO}_{4}, 20$ glucose, $2 \mathrm{MgCl}_{2}$, and $2 \mathrm{CaCl}_{2}$, at $34^{\circ} \mathrm{C}$, $\mathrm{pH}$ 7.4, gassed with $95 \% \mathrm{O}_{2}$ and $5 \% \mathrm{CO}_{2}$ ]. After $\sim 40$ min recovery time, slices were transferred to room temperature and were constantly perfused with ACSF.

Whole-cell patch-clamp recording was performed on neurons in layer $2 / 3(\mathrm{~L} 2 / 3)$ through $\mathrm{L} 5$ in the prelimbic $(\mathrm{PL})$ region of $\mathrm{mPFC}$. The PL region was identified based on the landmarks (forceps minor of the corpus callosum) and by measuring distance from the midline and the cortical surface. Neurons in the area of $0.15-0.5 \mathrm{~mm}$ from the midline and $1.2-1.8 \mathrm{~mm}$ from the cortical surface were regarded as belonging to L2/3 through L5 of the PL region. Recording was obtained with Multiclamp 
B

\section{A}

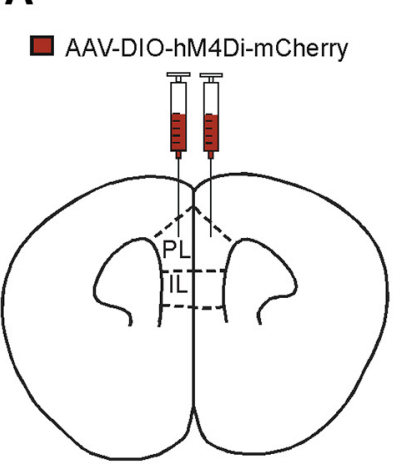

PV-Cre mouse

or

PV-Cre; H2B-GFP mouse

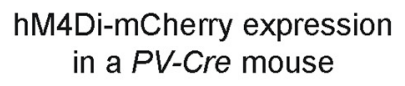

hM4Di-mCherry expression in a $P V$-Cre mouse
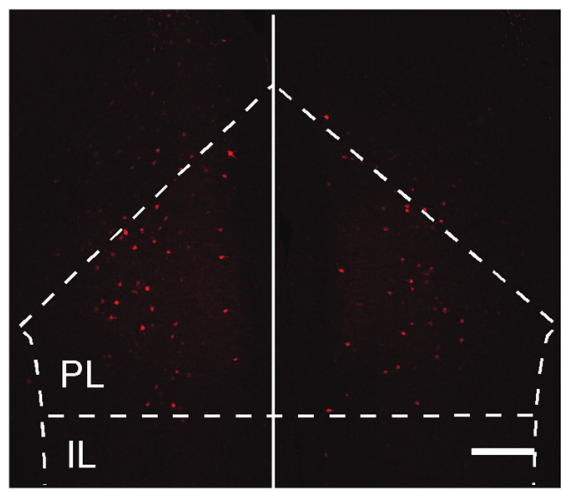

C

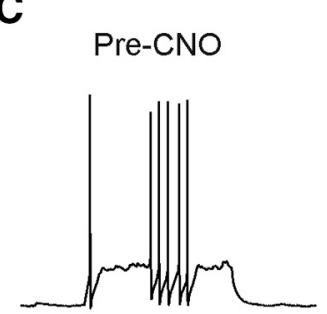

hM4Di-mCherry expression in a $P V-C r e ; H 2 B-G F P$ mouse
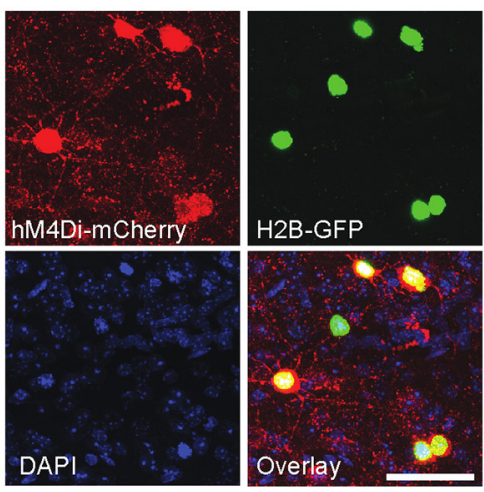

D

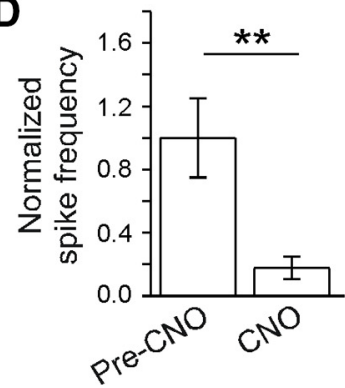

Figure 3. Selective suppression of PL PV interneurons with a pharmacogenetic approach. $A$, A schematic of injection. $\boldsymbol{B}$, Left, A representative image of infected neurons in the PL region. Scale bar, $200 \mu \mathrm{m}$. Right, Representative images showing selective expression of hM4Di-mCherry (red) in PL PV interneurons, which were labeled with H2B-GFP (green). Scale bar, $50 \mu \mathrm{m}$. C, Sample recording traces showing the effect of CNO bath application $(10 \mu \mathrm{m})$ on the spiking activity of mPFC PV neurons expressing hM4Di-mCherry. D, Quantification of the effect of hM4Di activation on $\mathrm{PV}$ cell firing. The firing rate of each neuron was normalized to the pre-CNO mean firing rate. CNO application significantly reduced PV cell firing rate $\left(n=6\right.$ cells $/ 3$ mice; $t_{(5)}=4.1 ;{ }^{* * *} p<0.01$, paired $t$ test). Data are shown as mean \pm SEM.

700B amplifiers (Molecular Devices) and was under visual guidance using an Olympus BX51 microscope equipped with both transmitted light illumination and epifluorescence illumination. Miniature postsynaptic currents were recorded in voltage-clamp mode with borosilicate pipettes (3.5-5 $\mathrm{M} \Omega$ ). For recording in voltage-clamp mode, the internal solution contained the following (in $\mathrm{mM}$ ): 115 cesium methanesulphonate, 20 CsCl, 10 HEPES, $2.5 \mathrm{MgCl}_{2}, 4 \mathrm{Na}_{2}$-ATP, $0.4 \mathrm{Na}_{3} \mathrm{GTP}, 10 \mathrm{Na}-$ phosphocreatine, and 0.6 EGTA, pH 7.2, with tetrodotoxin $(1 \mu \mathrm{M})$ added to the ACSF. mEPSCs were recorded at holding potential of $-70 \mathrm{mV}$, with picrotoxin $(100 \mu \mathrm{M})$ added to the ACSF. mIPSCs were recorded at a holding potential of $0 \mathrm{mV}$ with D-AP-5 (D-(-)-2-amino-5-phosphonopentanoic acid, $100 \mu \mathrm{M}$ ) and NBQX (2,3-dioxo-6-nitro-1,2,3,4tetrahydrobenzo[f] quinoxaline-7-sulfanamide, $3 \mu \mathrm{M}$ ) added to the ACSF. Electrophysiological data were acquired using pClamp 10 software (Molecular Devices) and analyzed using Mini Analysis Program (Synaptosoft).

To validate the effect of hM4Di, recording was performed in currentclamp mode. The internal solution consisted of the following (in $\mathrm{mm}$ ): 130 potassium gluconate, $5 \mathrm{KCl}, 10 \mathrm{HEPES}, 2.5 \mathrm{MgCl}$, $4 \mathrm{Na} 2 \mathrm{ATP}, 0.4$ Na3GTP, 10 sodium phosphocreatine, and 0.6 EGTA, pH 7.2. A small $500 \mathrm{~ms}$ current pulse was injected once every $10 \mathrm{~s}$ to produce a firing rate of $\geq 1.0 \mathrm{~Hz}$. After $5 \mathrm{~min}$ of stable recording, clozapine- $\mathrm{N}$-oxide (CNO; 10 $\mu \mathrm{M})$ was bath applied while recording continued.

Stereotaxic surgery and viral injection. Viral injection procedures were described previously (Li et al., 2011, 2013; Wang et al., 2014). The following stereotaxic coordinates were used for the mPFC: $1.94 \mathrm{~mm}$ anterior from Bregma, $0.45 \mathrm{~mm}$ lateral from midline, and $2.4 \mathrm{~mm}$ vertical from the cortical surface.

The AAV-DIO-hM4Di-mCherry and AAV-DIO-GFP viruses were produced by the University of North Carolina Vector Core Facilities. We injected $0.2-0.5 \mu$ l of viral solution $\left(\sim 10^{12}\right.$ virus particles $\left./ \mathrm{ml}\right)$ bilaterally into the mPFC of $P V$-Cre mice and waited 3-4 weeks to allow maximal viral expression.
Pharmacogenetic manipulation. Two groups of mice were used: (1) PVCre mice that received bilateral injections of AAV-DIO-hM4Di-mCherry $(n=24)$ and (2) PV-Cre mice that received bilateral injections of AAV-DIOGFP $(n=39)$ into the mPFC. All mice were injected intraperitoneally with CNO $(10 \mathrm{mg} / \mathrm{kg})$ at $30 \mathrm{~min}$ before the onset of each of the two LH induction sessions, and again at $30 \mathrm{~min}$ before the onset of the testing session. Behavioral data from animals in which viral injection missed target were excluded from the analysis.

Data analysis and statistics. Statistical tests were performed with GraphPad Prism and the R programming environment. All data were tested for normality with the Shapiro-Wilk normality test and for homogeneity of variances with the Fligner-Killen test, and log-transformed when necessary to fulfill ANOVA assumptions. Behavioral parameters for LH were analyzed with $k$-means cluster analysis and linear discriminant analysis (Fig. 1) and the Mann-Whitney test (see Fig. 4B, C); behavioral data for the OFT were analyzed with paired $t$ tests or the Wilcoxon signed-rank test (see Fig. 4D,E). Electrophysiological data was analyzed with nested one-way ANOVA followed by Tukey's test (Fig. 2) and paired $t$ test (Fig. 3).

\section{Results}

Adaptive and maladaptive behavioral responses induced by the learned helplessness procedure

To investigate neural mechanisms underlying the emergence of adaptive or maladaptive behavioral responses induced by stress, we used the well-established LH procedure, in which mice were subjected to unpredictable and inescapable footshocks (Chourbaji et al., 2005; Li et al., 2011; Wang et al., 2014; see Materials and Methods). Consistent with previous studies (Chourbaji et al., 2005; Wang et al., 2014), 24\% of mice (136 of 574) became helpless, whereas $\sim 76 \%$ (438 of 574 ) were resilient to helplessness after being subjected to this procedure. The separation of 
A
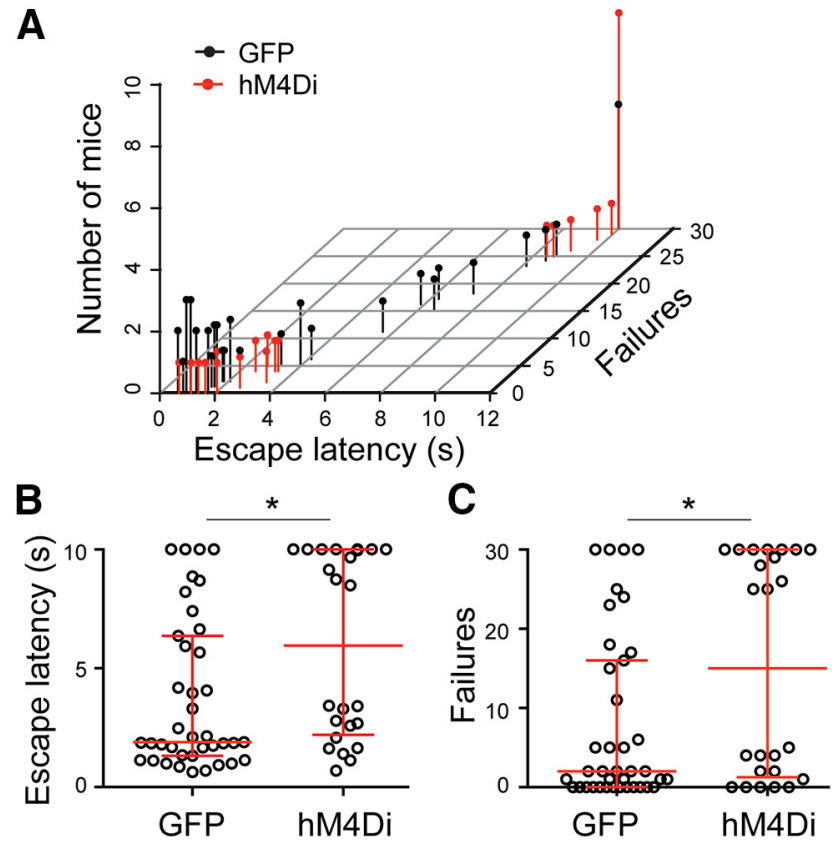

D

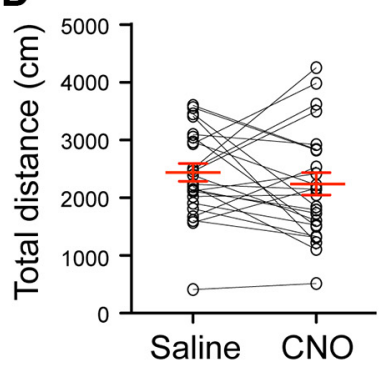

E

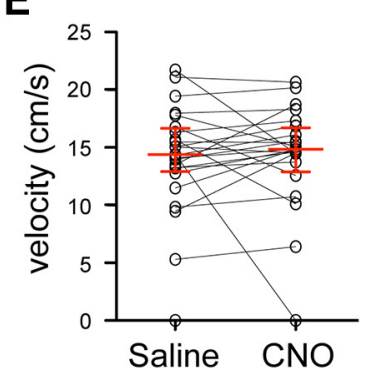

Figure 4. Pharmacogenetic suppression of PL PV interneuron activity promotes helplessness. $A, A$ 3D scatterplot of data from $P V$-Cre mice in which the PL region was injected with AAV-DIO-GFP (GFP group) or AAV-DI0-hM4Di (hM4Di group). The position of each dot along the $z$-axis represents the number of mice showing a specific set of behavioral parameters in the $L H$ test. $\boldsymbol{B}, \boldsymbol{C}$, Same data as in $\boldsymbol{A}$, except that the escape latencies $(\boldsymbol{B})$ and the numbers of failures $(\boldsymbol{C})$ of these mice are presented separately. ${ }^{*} p<0.05$. The median and interquartile ranges are shown in red. $\boldsymbol{D}, \boldsymbol{E}$, Total distance traveled ( $\boldsymbol{D}$; mean and SEM in red) and velocity in the center zone ( $\boldsymbol{E}$; median and interquartile range in red) measured in an open field for the hM4Di mice. The same mice were tested after both saline and CNO injection (counterbalanced; saline first, $n=12$ mice; (NO first, $n=12$ mice). Activation of hM4Di by CNO does not change locomotion.

mice into helpless and resilient groups was based on a $k$-means cluster analysis, using behavioral measurements - the number of failures and the latency to escape footshocks - obtained during a testing session as classification parameters (Fig. $1 A, B$; see Materials and Methods; Chourbaji et al., 2005; Wang et al., 2014). The helpless mice had significantly more failures and longer escape latencies than the resilient ones $\left(W_{(572)}=59568, p=2.2 \times\right.$ $10^{-16}$, and $W_{(572)}=59541, p=2.2 \times 10^{-16}$, respectively; twotailed Mann-Whitney test).

To facilitate the identification of neural changes potentially responsible for resilience or helplessness, in subsequent experiments we focused on mice that displayed the most extreme behavioral phenotypes: helpless mice that showed the most failures and longest escape latency, and resilient mice that had the least failures and shortest escape latency (Fig. 1C).

Modification of excitatory synaptic transmission onto mPFC PV interneurons by the learned helplessness procedure The PV neurons constitute a major class of GABAergic interneurons in the mPFC. To determine the role of mPFC PV interneu-

rons in stress-related behaviors, we examined whether synaptic transmission onto these neurons can be modified in response to the LH procedure. We took advantage of the PV-Cre;Ai14 mice, in which the Cre recombinase is expressed under the endogenous parvalbumin promoter (Hippenmeyer et al., 2005), and in which the red fluorescent reporter tdTomato is expressed in a Credependent manner (Madisen et al., 2010), allowing the PVexpressing cells to be readily identified by their red fluorescence.

We performed whole-cell patch-clamp recordings in acute slices prepared from naive, resilient, or helpless mice (Fig. 2A). We focused on the PL region of $\mathrm{MPFC}$, an area that has been implicated in executive functions and processing of aversive memories (Heidbreder and Groenewegen, 2003; Quirk and Beer, 2006) and has been involved in the LH behavior (Amat et al., 2005; Wang et al., 2014). We recorded miniature EPSCs and IPSCs that represent the net synaptic inputs onto the recorded cells.

Notably, the amplitude (but not frequency) of mEPSCs onto mPFC PV interneurons was significantly reduced in helpless mice compared with resilient or naive mice (amplitude, within groups (treatments), $F_{(2,13)}=5.33, p<0.05$; within subgroups (individual mice), $F_{(13,133)}=3.47, p<0.001$; frequency, within groups, $F_{(2,13)}=0.03, p=0.97$; within subgroups, $F_{(13,133)}=$ $1.44, p=0.15$, nested ANOVA; $p<0.001$, post hoc Tukey's test; $n=48$ cells $/ 5$ mice, 46 cells $/ 6$ mice, and 55 cells $/ 5$ mice for naive, resilient, and helplessness groups, respectively; Fig. $2 \mathrm{~B}, \mathrm{C}$ ). Further analysis based on cellular locations revealed that, compared to mice from the other two groups, the helpless mice had reduced amplitude of mEPSCs onto layer $5 \mathrm{PV}$ interneurons (within groups, $F_{(2,13)}=4.34, p<0.05$; within subgroups, $F_{(13,63)}=2.4$, $p<0.05$, nested ANOVA; $n=26$ cells $/ 5$ mice, 24 cells $/ 6$ mice, and 29 cells/ 5 mice for naive, resilient, and helpless groups, respectively), and had a trend toward reduced amplitude of mEPSCs onto layer 2/3 PV interneurons (within groups, $F_{(2,12)}=3.14$, $p=$ 0.08 ; within subgroups, $F_{(12,55)}=4.17, p<0.001$, nested ANOVA; $n=22$ cells $/ 4$ mice, 22 cells $/ 6$ mice, and 26 cells $/ 5$ mice for naive, resilient, and helpless groups, respectively).

No obvious difference was observed in mIPSCs onto these neurons across different groups of animals (amplitude, within groups, $F_{(2,10)}=0.45, p=0.65$; within subgroups, $F_{(10,54)}=2.16$, $p=0.03$; frequency, within groups, $F_{(2,10)}=1.49, p=0.27$; within subgroups, $F_{(10,54)}=1.94, p=0.06$, nested ANOVA; $n=$ 21 cells $/ 3$ mice, 21 cells $/ 4$ mice, and 25 cells $/ 6$ mice for naive, resilient, and helpless groups, respectively; Fig. $2 D, E)$. These results indicate that the strength of excitatory synapses onto PV interneurons in the PL region is selectively weakened in helpless mice.

\section{Suppression of PV interneurons in the mPFC promotes helplessness}

Depression of excitatory synaptic transmission presumably reduces neuronal activation in response to excitatory inputs. To determine whether reduced activity of PV interneurons in the PL region contributes to the development of helpless behavior, we took a pharmacogenetic approach (Rogan and Roth, 2011) to selectively suppress the activity of these neurons. To this end, we bilaterally injected the PL region of $\mathrm{PV}$-Cre mice with an AAVDIO-hM4Di-mCherry (Fig. 3A), a double floxed inverted open reading frame adenoassociated virus (AAV-DIO) that expresses, in a Cre-dependent manner, an engineered $\mathrm{G}_{\mathrm{i}}$-coupled receptor hM4Di [the "DREADD" (designer receptor exclusively activated by designer drug)] tagged with a fluorescent protein mCherry (hM4Di-mCherry). This strategy selectively targeted PL PV in- 
terneurons (Fig. 3B), which can subsequently be suppressed by treating mice with $\mathrm{CNO}$, the agonist of hM4Di (Rogan and Roth, 2011). We confirmed that this approach suppressed firing of PV interneurons in the mPFC (Fig. 3C,D), consistent with our previous result (Li et al., 2013). In addition, it has been shown that activation of hM4Di leads to suppression of neurotransmitter release from infected neurons (Stachniak et al., 2014).

Remarkably, selective suppression of mPFC PV interneurons during the LH procedure (see Materials and Methods) resulted in a significant increase in the escape latency (GFP group, $n=39$; hM4Di group, $n=24 ; W_{(61)}=303.5 ; p=0.019$, two-tailed Mann-Whitney test $)$ and the number of failures $\left(W_{(61)}=320.5\right.$; $p=0.034$, two-tailed Mann-Whitney test; Fig. $4 A-C$ ), which are the most commonly reported indices of helplessness (Chourbaji et al., 2005; Wang et al., 2014). Importantly, suppression of PV interneurons in the PL region did not affect locomotion in an open field test (total distance, $t_{(23)}=1.024, p=0.32$, paired $t$ test; velocity in the center zone, $W_{(23)}=-58, p=0.39$, Wilcoxon signed-rank test; Fig. $4 D, E$ ), indicating that the observed behavioral phenotype in the LH procedure is not caused by nonspecific motor deficit.

\section{Discussion}

In this study, we focused on the role of PV interneurons in the mPFC in the learned helplessness model of depression. We found that the uncontrollable and inescapable stressor used in this model induces weakening of excitatory synaptic transmission onto these neurons specifically in mice showing helplessness. This stressinduced decrease in excitatory drive may reduce the activity of PV interneurons required for shaping adaptive behavioral responses in the face of adverse life events, thereby contributing to the development of helplessness. Indeed, pharmacogenetic suppression of mPFC PV interneurons during the LH procedure promoted helpless behavioral responses. These results, together with our previous finding that enhanced excitatory synaptic transmission onto pyramidal neurons in the $\mathrm{mPFC}$ promotes helplessness (Wang et al., 2014), suggest that an imbalance of excitation and inhibition within the MPFC microcircuits, manifested as aberrant changes in synapses onto either inhibitory PV interneurons or excitatory principal neurons, might represent a critical feature of the pathophysiological process underlying depression and related mental disorders.

Cortical PV interneurons greatly influence the timing and pattern of pyramidal cell firing, and are involved in the generation and maintenance of network oscillations (Cardin et al., 2009; Courtin et al., 2014). The behavioral role of PV interneurons has been difficult to address. However, with the advent of new techniques that allow selective monitoring and manipulation of genetically defined cell types, previous studies started to reveal the role of MPFC PV interneurons in initiating or coordinating specific behaviors, including defensive responses (Courtin et al., 2014). Our study reveals a previously unknown mechanism of stress response in the $\mathrm{mPFC}$, and strongly points to the involvement of mPFC PV interneurons in the development of adaptive and maladaptive behaviors and in the pathogenesis of mood disorders.

\section{References}

Amat J, Baratta MV, Paul E, Bland ST, Watkins LR, Maier SF (2005) Medial prefrontal cortex determines how stressor controllability affects behavior and dorsal raphe nucleus. Nat Neurosci 8:365-371. CrossRef Medline

Cardin JA, Carlén M, Meletis K, Knoblich U, Zhang F, Deisseroth K, Tsai LH,
Moore CI (2009) Driving fast-spiking cells induces gamma rhythm and controls sensory responses. Nature 459:663-667. CrossRef Medline

Chourbaji S, Zacher C, Sanchis-Segura C, Dormann C, Vollmayr B, Gass P (2005) Learned helplessness: validity and reliability of depressive-like states in mice. Brain Res Brain Res Protoc 16:70-78. CrossRef Medline

Courtin J, Chaudun F, Rozeske RR, Karalis N, Gonzalez-Campo C, Wurtz H, Abdi A, Baufreton J, Bienvenu TC, Herry C (2014) Prefrontal parvalbumin interneurons shape neuronal activity to drive fear expression. Nature 505:92-96. Medline

Dias-Ferreira E, Sousa JC, Melo I, Morgado P, Mesquita AR, Cerqueira JJ, Costa RM, Sousa N (2009) Chronic stress causes frontostriatal reorganization and affects decision-making. Science 325:621-625. CrossRef Medline

Drevets WC, Price JL, Furey ML (2008) Brain structural and functional abnormalities in mood disorders: implications for neurocircuitry models of depression. Brain Struct Funct 213:93-118. CrossRef Medline

Goldwater DS, Pavlides C, Hunter RG, Bloss EB, Hof PR, McEwen BS, Morrison JH (2009) Structural and functional alterations to rat medial prefrontal cortex following chronic restraint stress and recovery. Neuroscience 164:798 808. CrossRef Medline

He M, Liu Y, Wang X, Zhang MQ, Hannon GJ, Huang ZJ (2012) Cell-typebased analysis of microRNA profiles in the mouse brain. Neuron 73:3548. CrossRef Medline

Heidbreder CA, Groenewegen HJ (2003) The medial prefrontal cortex in the rat: evidence for a dorso-ventral distinction based upon functional and anatomical characteristics. Neurosci Biobehav Rev 27:555-579. CrossRef Medline

Hippenmeyer S, Vrieseling E, Sigrist M, Portmann T, Laengle C, Ladle DR, Arber S (2005) A developmental switch in the response of DRG neurons to ETS transcription factor signaling. PLoS Biol 3:e159. CrossRef Medline

Kendler KS, Karkowski LM, Prescott CA (1999) Causal relationship between stressful life events and the onset of major depression. Am J Psychiatry 156:837-841. CrossRef Medline

Li B, Piriz J, Mirrione M, Chung C, Proulx CD, Schulz D, Henn F, Malinow R (2011) Synaptic potentiation onto habenula neurons in the learned helplessness model of depression. Nature 470:535-539. CrossRef Medline

Li H, Penzo MA, Taniguchi H, Kopec CD, Huang ZJ, Li B (2013) Experience-dependent modification of a central amygdala fear circuit. Nat Neurosci 16:332-339. CrossRef Medline

Madisen L, Zwingman TA, Sunkin SM, Oh SW, Zariwala HA, Gu H, Ng LL, Palmiter RD, Hawrylycz MJ, Jones AR, Lein ES, Zeng H (2010) A robust and high-throughput Cre reporting and characterization system for the whole mouse brain. Nat Neurosci 13:133-140. CrossRef Medline

Maier SF (1984) Learned helplessness and animal models of depression. Prog Neuropsychopharmacol Biol Psychiatry 8:435-446. CrossRef Medline

Price JL, Drevets WC (2012) Neural circuits underlying the pathophysiology of mood disorders. Trends Cogn Sci 16:61-71. CrossRef

Quirk GJ, Beer JS (2006) Prefrontal involvement in the regulation of emotion: convergence of rat and human studies. Curr Opin Neurobiol 16: 723-727. CrossRef Medline

Rajkowska G, O’Dwyer G, Teleki Z, Stockmeier CA, Miguel-Hidalgo JJ (2007) GABAergic neurons immunoreactive for calcium binding proteins are reduced in the prefrontal cortex in major depression. Neuropsychopharmacology 32:471-482. CrossRef Medline

Rogan SC, Roth BL (2011) Remote control of neuronal signaling. Pharmacol Rev 63:291-315. CrossRef Medline

Savitz JB, Price JL, Drevets WC (2014) Neuropathological and neuromorphometric abnormalities in bipolar disorder: view from the medial prefrontal cortical network. Neurosci Biobehav Rev 42:132-147. CrossRef Medline

Seligman ME (1978) Learned helplessness as a model of depression. Comment and integration. J Abnorm Psychol 87:165-179. CrossRef Medline

Stachniak TJ, Ghosh A, Sternson SM (2014) Chemogenetic synaptic silencing of neural circuits localizes a hypothalamus $\rightarrow$ midbrain pathway for feeding behavior. Neuron 82:797-808. CrossRef Medline

Wang M, Perova Z, Arenkiel BR, Li B (2014) Synaptic modifications in the medial prefrontal cortex in susceptibility and resilience to stress. J Neurosci 34:7485-7492. CrossRef Medline

Yuen EY, Liu W, Karatsoreos IN, Ren Y, Feng J, McEwen BS, Yan Z (2011) Mechanisms for acute stress-induced enhancement of glutamatergic transmission and working memory. Mol Psychiatry 16:156-170. CrossRef Medline 